\title{
Construction of a blood-compatible interface based on surface segregation in a polymer blend
}

Toyoaki Hirata ${ }^{\mathrm{a}}$, Hisao Matsuno, ${ }^{\mathrm{a},{ }^{*}}$, Daisuke Kawaguchi ${ }^{\mathrm{b}}$, Norifumi L. Yamada ${ }^{\mathrm{c}}$, Masaru Tanaka $^{\mathrm{d}}$, and Keiji Tanaka ${ }^{\text {a,e,* }}$

${ }^{a}$ Department of Applied Chemistry, Kyushu University, Fukuoka 819-0395, Japan

${ }^{\mathrm{b}}$ Education Center for Global Leaders in Molecular Systems for Devices, Kyushu University, Fukuoka 819-0395, Japan

${ }^{c}$ Neutron Science Laboratory, High Energy Accelerator Research Organization, Ibaraki 305-0801, Japan

${ }^{\mathrm{d}}$ Department of Biochemical Engineering, Yamagata University, Yamagata 992-8510, Japan

(Present Address, Institute for Materials Chemistry and Engineering, Kyushu University, Fukuoka 819-0395, Japan)

${ }^{\mathrm{e}}$ International Institute for Carbon-Neutral Energy Research (WPI-I2CNER), Kyushu University, Fukuoka 819-0395, Japan

*To whom correspondence should be addressed

FAX: +81-92-802-2880 TEL: +81-92-802-2879(HM) and +81-92-802-2878 (KT)

E-mail: h-matsuno@cstf.kyushu-u.ac.jp (HM) and k-tanaka@cstf.kyushu-u.ac.jp (KT) 


\section{ABSTRACT}

The technique of surface segregation was applied to prepare a bio-inert polymer interface. A small amount, $10 \mathrm{wt} \%$, of poly(2-methoxyetyl acrylate) (PMEA), which exhibits excellent bio-inertness properties, fed into a matrix polymer was able to suppress platelet adhesion sufficiently to be of practical use. PMEA was effective because it was preferentially segregated at the outermost region of the polymer blend. Combining interfacial-sensitivity analyses such as the air bubble contact angle and neutron reflectivity measurements and sum-frequency generation spectroscopy with the platelet adhesion test gives a better understanding of how the bio-inert property is expressed at the water interface. 


\section{Introduction}

Surface functionalization is of growing interest for many industrial and medical applications to enhance the value of the materials used in these fields. Thus, various chemical and physical methods to optimize surface properties have been proposed [1-16]. Blending different kinds of polymers is one such technology [4-12]. When a polymer "A" with a lower surface free energy is mixed into a different polymer "B", "A" is preferentially partitioned into the surface. This phenomenon is called surface segregation [4-12]. Thus, if polymer "A" possesses a special function, the surface property of polymer "B" is consequently modified. This method of surface modification is quite simple and does not need special apparatus unlike other methods such as chemical reaction $[1-3,13,14]$, corona $[15,16]$ and plasma treatment $[17,18]$. The most intriguing advantage of this method is that the surface so modified is more robust because the surface segregation is driven by thermodynamics. In addition, this technique can be applied to a valuable polymer because even though a small amount of the polymer is fed into a matrix polymer, it should all be concentrated at the surface.

Previously, we applied this method to prepare a thin film, in which the outermost region was fully covered with poly(2-methoxyethyl acrylate) (PMEA) [19], a typical bioinert polymer [20-22]. Although PMEA is in a rubbery state under physiological conditions due to its low glass transition temperature $\left(T_{\mathrm{g}}\right)$, a sufficiently stable and flat PMEA surface could be constructed by adding a polymer known to be glassy, poly(methyl methacrylate) (PMMA) [19]. The enrichment of PMEA even took place at the interface with water. Using various techniques to measure interfacial-sensitivity, we have succeeded in gaining a better understanding of aggregation states and interfacial dynamics of PMEA at the water interface and learning more about the effects of the aggregation states on the bio-inert properties of PMEA $[23,24]$. In previous studies, the blend ratio of PMEA to PMMA was set at 50/50 (wt/wt) to ensure perfect coverage with PMEA at the outermost water interface $[19,23,24]$. Here, we show that a small amount of PMEA, $10 \mathrm{wt} \%$, fed into PMMA was sufficient to exhibit bio-inertness at a level of practical use to enable platelet adhesion. 


\section{Experimental section}

\subsection{Materials}

Polydisperse PMEA at a quality level that can be produced at the industrial scale for use in medical applications was synthesized by free-radical polymerization [19]. Commercially-available monodisperse PMMA and deuterated PMMA (dPMMA) synthesized by living anionic polymerization were used. Characteristics of the polymers determined by gel permeation chromatography (GPC) and differential scanning calorimetry (DSC) are summarized in Table 1.

Table 1. Characteristics of polymers used in this study.

\begin{tabular}{cccc}
\hline Polymer & $M_{\mathrm{n}}^{\mathrm{a}}$ & $\mathrm{PDI}^{\mathrm{b}}$ & $T_{\mathrm{g}}^{\mathrm{c}} / \mathrm{K}$ \\
\hline PMEA & $26 \mathrm{k}$ & 3.23 & 240 \\
PMMA & $85 \mathrm{k}$ & 1.09 & 401 \\
dPMMA & $93 \mathrm{k}$ & 1.07 & 403 \\
${ }^{\mathrm{a}} M_{\mathrm{n}} ;$ & The number-average molecular & weight determined by $\mathrm{GPC}$ \\
calibrated using PMMA standards. & \\
${ }^{\mathrm{b}}$ PDI; polydispersity index determined by GPC. \\
${ }^{\mathrm{c}} T_{\mathrm{g}}$; The bulk grass-transition temperature determined by DSC.
\end{tabular}

\subsection{Film preparation}

Thin PMEA/PMMA and PMEA/dPMMA blend films with a thickness of approximately $60 \mathrm{~nm}$ were prepared onto $\mathrm{SiO}_{\mathrm{x}}$ substrates. The blend ratio of PMEA/(d)PMMA was adjusted to a weight ratio of $10 / 90(\mathrm{wt} / \mathrm{wt})$. These films were dried in a vacuum oven at room temperature for $24 \mathrm{~h}$ and subsequently annealed for $6 \mathrm{~h}$ at $413 \mathrm{~K}$ which was above the $T_{\mathrm{g}}$ of 375 (377) $\mathrm{K}$ calculated based on the Fox equation [25] and below the phase separation temperature of 457 (456) K calculated based on the Flory-Huggins equation [26] for PMEA/(d)PMMA blends. Phase separation did not occur for these blend films containing $10 \mathrm{wt} \%$-PMEA at the temperatures employed. That is, the system was always miscible as previously reported [19]. 


\subsection{Atomic force microscopic (AFM) observations}

The surface morphology of the blend films was examined by AFM (Agilent Technologies 5500 Scanning Probe Microscope, Agilent Technologies, Inc., Santa Clara, CA, US) using an intermittent contact mode at room temperature in water. The cantilever tip used for the measurement was microfabricated from $\mathrm{Si}$, and its spring constant and resonance frequency in air were $2.8 \mathrm{~N} \cdot \mathrm{m}^{-1}$ and 75 $\mathrm{kHz}$, respectively. The tip radius was approximately $5 \mathrm{~nm}$. The drive frequency used in water was 30 $\mathrm{kHz}$, which was on the lower frequency side of the resonance. To avoid possible deformations of the sample surface during the observation, the ratio of the set point to the free amplitude of the cantilever was maintained at approximately 0.9 (10\% damping of the amplitude of oscillation).

\subsection{Contact angle measurements}

The blend films were characterized at the water interface by static contact angle $(\theta)$ measurements at room temperature using an air bubble as a probe. The $\theta$ value was recorded as a function of the immersion time in water using a Drop Master 500 (Kyowa Interface Science Co. Ltd., Niiza, Japan). The first $\theta$ value was obtained immediately after film immersion into water, and the time interval between measurements was set to be $30 \mathrm{~min}$ up to $24 \mathrm{~h}$.

\subsection{Neutron reflectivity (NR) measurements}

The density profile of the blend films along the depth direction was examined by NR with a SOFIA reflectometer at the Materials and Life Science Experimental Facility, Japan Proton Accelerator Research Complex (J-PARC) [27,28]. A Teflon-made reservoir filled with $\mathrm{D}_{2} \mathrm{O}$ was mounted onto the film. The measurements were conducted in air, and then, in $\mathrm{D}_{2} \mathrm{O}$ after pre-immersion for $24 \mathrm{~h}$ at room temperature, which enables the film structure to reach a quasi-equilibrium state. A beam of neutrons with a wavelength $(\lambda)$ that ranged from 0.25 to $0.88 \mathrm{~nm}$ at a resolution of $3 \%$ was guided into the specimen from the quartz side. Details of our experimental setup are described elsewhere $[29,30]$. The 
reflectivity was calculated on the basis of the model $(b / V)$ profile along the depth direction by means of Parratt32 software, a freeware program from the Hahn-Meitner Institute (HMI). The $(b / V)$ values of PMEA, PMMA, dPMMA, $\mathrm{SiO}_{2}$, and $\mathrm{D}_{2} \mathrm{O}$ used for the calculation were $1.15 \times 10^{-4}, 1.04 \times 10^{-4}, 7.02 \times 10^{-4}$, $3.48 \times 10^{-4}$, and $6.38 \times 10^{-4} \mathrm{~nm}^{-2}$, respectively.

\subsection{Sum-frequency generation (SFG) spectroscopy}

The aggregation states of polymers and water at the interface were examined by SFG measurements [31-35]. SFG spectra were collected with visible light with a $\lambda$ of $532 \mathrm{~nm}$ and tunable infrared (IR) beams traveling through the prism and overlapping at the interface between film and air or $\mathrm{H}_{2} \mathrm{O}$. The measurements were carried out at room temperature using one type of polarization combination, namely ssp (SF output, visible input, and infrared input). Details of our experimental setup are described elsewhere [34].

\subsection{Platelet adhesion tests}

Blood was drawn from healthy volunteers and mixed with sodium citrate. The platelet-rich plasma was then obtained by centrifugation $[20,21]$. The platelet concentration was determined by an automated hematology analyzer. Before the tests, the films were immersed in water for a predetermined time. Then, the platelet suspension was placed on each film surface at room temperature for $1 \mathrm{~h}$. After washing the platelets with phosphate buffered saline (PBS), the adhered platelets were fixed by immersing the films in glutaraldehyde in PBS. Samples were freeze-dried prior to scanning electron microscopy.

\section{Results and discussion}

Panels (a, b) of Fig. 1 show AFM height and phase images, respectively, of the PMEA/PMMA (10/90) blend film immersed in water for $24 \mathrm{~h}$. Both images were featureless, meaning that the blend 
film was miscible and structurally stable without any collapse from conditions like dewetting and dissolution, even in water. Panel (c) of Fig. 1 is a sectional view along the line in panel (a). Solid circles in panel (d) of Fig. 1 show a root-mean-square surface roughness $\left(R_{\mathrm{rms}}\right)$ for the blend film as a function of immersion time in water. The $R_{\mathrm{rms}}$ values were approximately $0.31 \mathrm{~nm}$ and remained unchanged for $24 \mathrm{~h}$, indicating that the flatness of the blend film at the outermost region could be kept at the nanometer-level, even in water.

(a)

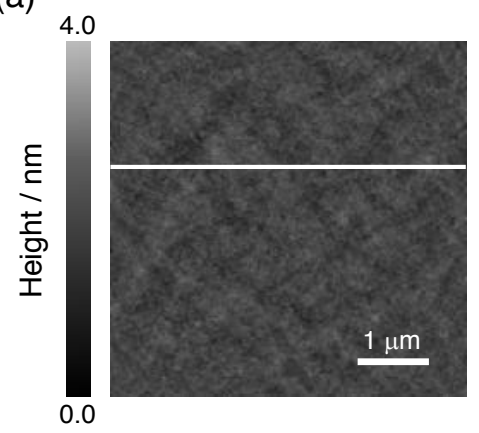

(c)

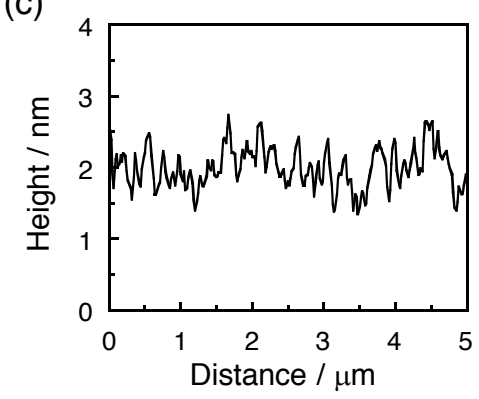

(b)

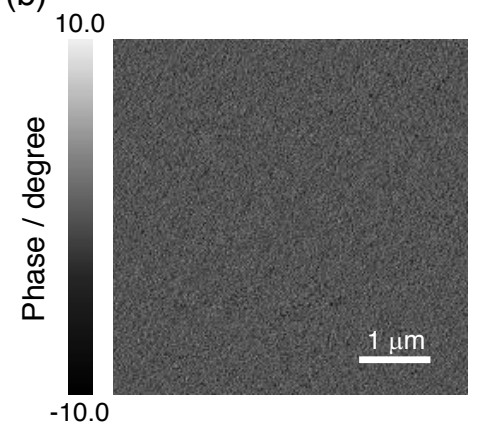

(d)

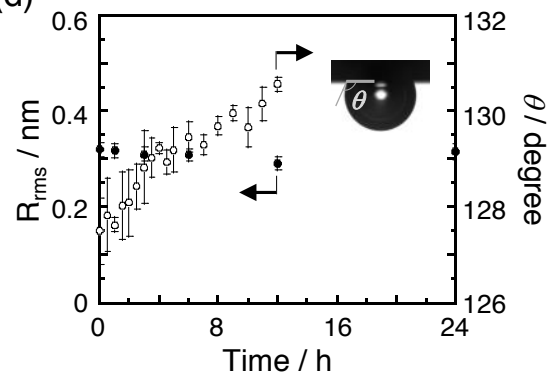

Fig. 1. AFM (a) height and (b) phase images for the PMEA/PMMA blend film. (c) A sectional view along a line in (a). (d) Solid circles denote the time-dependence of $R_{\text {rms }}$ values determined by AFM height images. Open circles denote the $\theta$ values determined by contact angle measurements using an air bubble as a probe.

While the interfacial roughening of the blend film did not occur in water, the bubble contact angle $(\theta)$ on the blend film measured in water clearly changed with increasing immersion time, as shown by open circles in Fig. 1(d). The initial $\theta$ value of $127.5 \pm 0.7^{\circ}$ right after water immersion slightly increased to $130.6 \pm 0.2^{\circ}$ after $12 \mathrm{~h}$, meaning that the structural reorganization of the blend, or PMEA, occurred at the water interface. After $12.5 \mathrm{~h}$, an air bubble could not be attached to the blend film; therefore, further measurements were truncated. The same phenomenon was observed for the PMEA/PMMA (50/50) 
blend [24]. However, the final $\theta$ value was lower for the PMEA/PMMA (10/90) blend than for the PMEA/PMMA (50/50) blend by approximately $4^{\circ}$. In addition, the time before an air bubble could not attach to the blend film was later for the PMEA/PMMA (10/90) blend than for the PMEA/PMMA (50/50) blend by approximately $3 \mathrm{~h}$. These differences imply that, rather than the PMEA/PMMA (50/50) blend film being fully covered with PMEA, PMMA somehow exists at the outermost region of the PMEA/PMMA (10/90) film in water after some time has passed.

To clarify this phenomenon, the density profile in the blend films along the direction normal to the surface was examined by specular NR measurements in air and $\mathrm{D}_{2} \mathrm{O}$. Panel (a) of Fig. 2 shows the scattering vector $\left(q_{z}\right)$ dependence of NR for the PMEA/dPMMA (10/90) film in air and $\mathrm{D}_{2} \mathrm{O}$. The data for $\mathrm{D}_{2} \mathrm{O}$ was offset by two decades for sake of clarity. The solid curves in panel (a) were calculated based on model $(b / V)$ profile shown in panel $(b)$, representing the best fit to the experimental data, shown by open circles. To simplify the fitting model, the film was divided into three layers with a Gaussian roughness at each interface, $\sigma_{\mathrm{i}}$, as shown in panel (e) of Fig. 2. The layers 1 and 3 correspond to the segregation layers. Table 2 summarizes the parameters used for fitting, where $t$ and $\xi$ represent the total film thickness and the decay length for the preferential segregation of $\mathrm{D}_{2} \mathrm{O}$ at the substrate interface. In general, according to the mean field approximation, the composition profile of a miscible polymer mixture in the surface region is expressed by a simple exponential decay function [36]. However, the experimental NR data obtained here did not fit well with such a function. Thus, the following $(b / V)$ profile was adopted:

$$
(b / V)(z)=\sum_{i=1}^{N} \frac{(b / V)_{i}-(b / V)_{i+1}}{2}\left\{1+\operatorname{erf}\left(\frac{z-z_{i}}{\sqrt{2} \sigma_{i}}\right)\right\}
$$

where $N$ and $z$ are the number of layers and the depth, respectively. The fit was judged based on the $\chi^{2}$ correlation. Assuming the incompressibility of the polymer chains, the average $(b / V)$ value for the PMEA/dPMMA blend with $9 / 91(\mathrm{v} / \mathrm{v})$ in air was calculated to be $6.49 \times 10^{-4} \mathrm{~nm}^{-2}$. While the $(b / V)_{1}$ of $2.78 \times 10^{-4} \mathrm{~nm}^{-2}$ and $(b / V)_{3}$ of $2.69 \times 10^{-4} \mathrm{~nm}^{-2}$ values were much smaller than the average $(b / V)$ value, 
the $(b / V)_{2}$ value of $6.90 \times 10^{-4} \mathrm{~nm}^{-2}$ was slightly larger than average. This means that the PMEA component with a lower $(b / V)$ value was enriched at both the air and substrate interfaces. As a result, the volume fraction of PMEA at the air interface was estimated to be $62 \%$, which was in good accordance with the data (61\%) obtained by angular-dependent X-ray photoelectron spectroscopy [19].
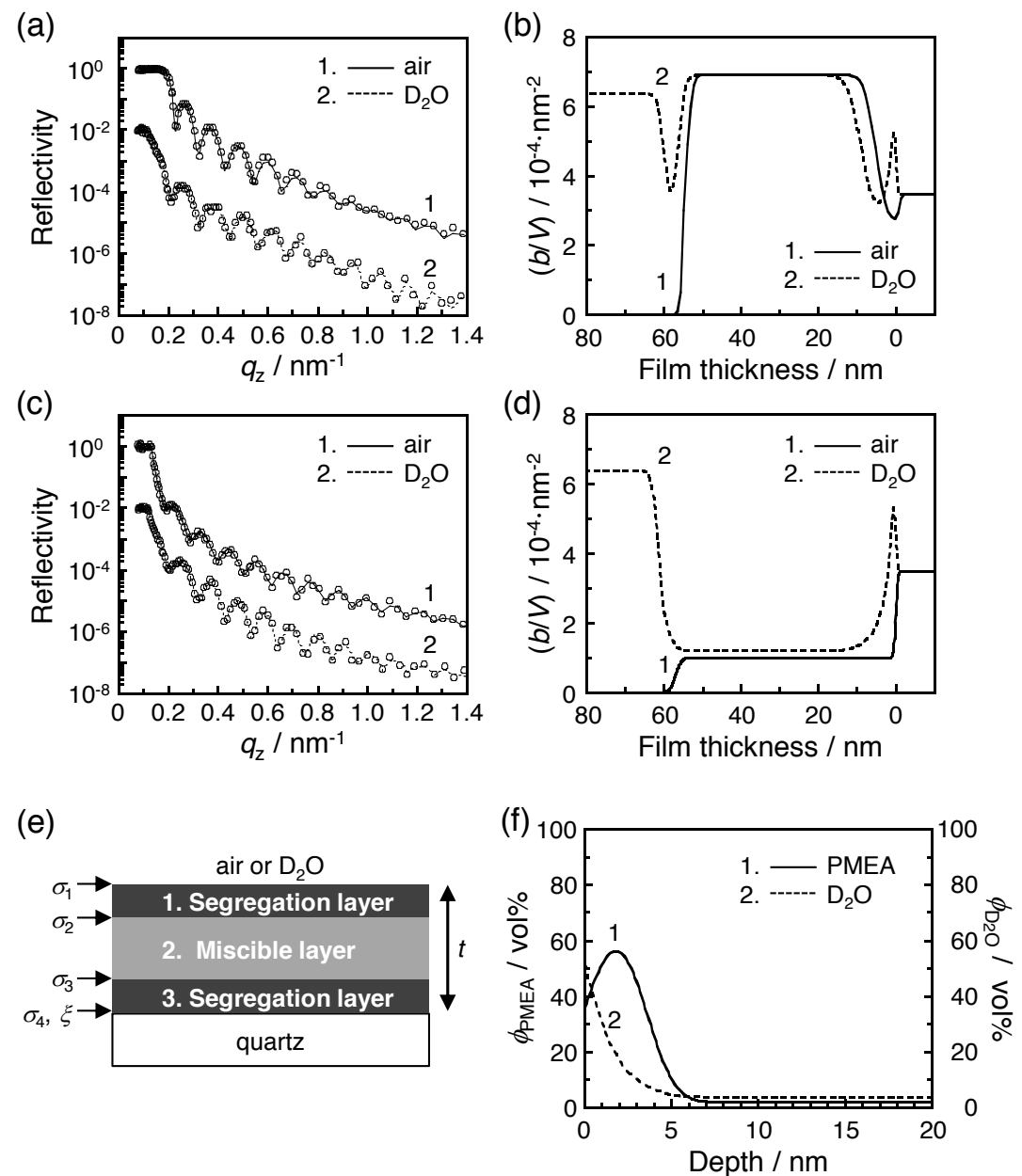

Fig. 2. NR curves for (a) PMEA/dPMMA and (c) PMEA/PMMA blend films in air and $\mathrm{D}_{2} \mathrm{O}$. Open symbols denote the experimental data and solid and dotted curves are the calculated reflectivity based on model $(b / V)$ profiles in panels (b and d) for (a and c), respectively. (e) A schematic illustration of the model used for fitting. (f) Enlarged depth dependence of $\phi_{\text {PMEA }}$ and $\phi_{\mathrm{D}_{2} \mathrm{O}}$ in the blend film near the $\mathrm{D}_{2} \mathrm{O}$ interface. The $\mathrm{x}$-axis denotes the depth from the $\mathrm{D}_{2} \mathrm{O} /$ polymer interface.

The periodicity of Kiessig fringes for the PMEA/dPMMA film in $\mathrm{D}_{2} \mathrm{O}$ became smaller than that obtained in air, indicating that the film became thicker in $\mathrm{D}_{2} \mathrm{O}$ (Fig. 2(a)). The original thickness of 55.8 $\mathrm{nm}$ increased to $59.9 \mathrm{~nm}$ in $\mathrm{D}_{2} \mathrm{O}$, as shown by the $t$ value in Table 2. This observation makes it clear that the blend film was definitely swollen by $\mathrm{D}_{2} \mathrm{O}$. The obtained $(b / V)$ values for the layers 1,2 and 3 in 
$\mathrm{D}_{2} \mathrm{O}$ were $2.79 \times 10^{-4}, 6.89 \times 10^{-4}$ and $2.63 \times 10^{-4} \mathrm{~nm}^{-2}$, respectively (Table 2). These values can be understood by taking into account $\mathrm{D}_{2} \mathrm{O}$ penetration into the film in addition to the interfacial segregation of PMEA. The $\sigma_{1}$ value at the $\mathrm{D}_{2} \mathrm{O}$ interface was $1.4 \mathrm{~nm}$ and larger than the value at the air interface $(0.7 \mathrm{~nm})$. This means that the outermost interface became more diffused in contact with $\mathrm{D}_{2} \mathrm{O}$.

Table 2. Parameters used to fit experimental reflectivity curves

\begin{tabular}{cccccccccccc}
\hline \multirow{2}{*}{ Blend film } & \multirow{2}{*}{ Medium } & \multicolumn{3}{c}{$(b / V)_{\mathrm{i}} / 10^{-4} \mathrm{~nm}^{-2}$} & \multicolumn{7}{c}{$\sigma_{\mathrm{i}} / \mathrm{nm}$} \\
& & $(b / V)_{1}$ & $(b / V)_{2}$ & $(b / V)_{3}$ & $t / \mathrm{nm}$ & $\sigma_{1}$ & $\sigma_{2}$ & $\sigma_{3}$ & $\sigma_{4}$ & $\xi / \mathrm{nm}$ & \multirow{2}{*}{$\chi^{2}$} \\
\hline PMEA/dPMMA & air & 2.78 & 6.90 & 2.69 & 55.8 & 0.7 & 1.2 & 2.3 & 0.5 & - & $8.0 \times 10^{-3}$ \\
PMEA/dPMMA & $\mathrm{D}_{2} \mathrm{O}$ & 2.79 & 6.89 & 2.63 & 59.9 & 1.4 & 1.4 & 2.8 & 0.5 & 2.0 & $5.9 \times 10^{-3}$ \\
PMEA/PMMA & air & 1.05 & - & - & 56.9 & 0.6 & - & - & 0.4 & - & $5.1 \times 10^{-3}$ \\
PMEA/PMMA & $\mathrm{D}_{2} \mathrm{O}$ & 1.76 & 1.20 & 1.56 & 61.4 & 1.4 & 1.4 & 2.8 & 0.4 & 2.0 & $4.2 \times 10^{-3}$ \\
\hline
\end{tabular}

The NR measurement was also applied to a PMEA/PMMA film with a very similar thickness to address the depth profile of the composition in this blend film under an aqueous environment. The data are shown in panels (c and d) of Fig. 2, and the parameters used to fit the curve to the reflectivity results are collected in Table 2. Panel (f) of Fig. 2 shows the depth dependence of the volume fraction of PMEA $\left(\phi_{\text {PMEA }}\right)$ and $\mathrm{D}_{2} \mathrm{O}\left(\phi_{\mathrm{D}_{2} \mathrm{O}}\right)$ in the blend film in close proximity to the $\mathrm{D}_{2} \mathrm{O}$ interface by combining NR data for the PMEA/dPMMA and PMEA/PMMA blend films in $\mathrm{D}_{2} \mathrm{O}$.

The number computed as one minus the sum of the fractions of PMEA and $\mathrm{D}_{2} \mathrm{O}$ corresponds to the dPMMA fraction at a certain depth. Table 3 summarizes the volume fraction of each component at the outermost interface $(i . e . d=0)$. The $\phi_{\mathrm{PMEA}}(0), \phi \mathrm{d}_{\mathrm{PMMA}}(0)$, and $\phi_{\mathrm{D}_{2} \mathrm{O}}(0)$ values were $35.6,12.5$ and 51.9 vol\%, respectively, for the PMEA/dPMMA (10/90) blend film. If $\mathrm{D}_{2} \mathrm{O}$ is not counted, $\phi_{\mathrm{PMEA}}(0)$ is approximately 74 vol\%, which was larger than the value obtained in air (62 vol\%). That is, the segregation of PMEA to the outermost region in the film was enhanced due to contact with $\mathrm{D}_{2} \mathrm{O}$. However, unlike the PMEA/dPMMA (50/50) blend, in which the outermost region was completely covered with PMEA, 12.5 vol\%-PMMA existed at the outermost region in the PMEA/dPMMA (10/90) blend film. This is consistent with the results of the air bubble contact angle measurements described 
above.

Table 3. The volume fraction of each component at $d=0$ in $\mathrm{D}_{2} \mathrm{O}$.

\begin{tabular}{cccc}
\hline $\begin{array}{c}\text { Blend ratio } \\
(\mathrm{wt} / \mathrm{wt})\end{array}$ & $\begin{array}{c}\phi_{\mathrm{PMEA}}(0) \\
/ \mathrm{vol} \%\end{array}$ & $\begin{array}{c}\phi_{\mathrm{dPMMA}}(0) \\
/ \mathrm{vol} \%\end{array}$ & $\begin{array}{c}\phi_{\mathrm{D}_{2} \mathrm{O}}(0) \\
/ \mathrm{vol} \%\end{array}$ \\
\hline $10 / 90$ & 35.6 & 12.5 & 51.9 \\
$50 / 50$ & $44.5^{\mathrm{a}}$ & $0^{\mathrm{a}}$ & $55.5^{\mathrm{a}}$ \\
\hline
\end{tabular}

${ }^{\mathrm{a}}$ The data are reported in a previous study [21].

Fig. 3 shows the SFG spectra representing local conformation of the PMEA/PMMA blend films at the air and $\mathrm{H}_{2} \mathrm{O}$ interfacial regions obtained with the ssp polarization combination, representing the information along the direction normal to the interface [24,31-35]. While a strong peak in the range of 2800-2900 $\mathrm{cm}^{-1}$ attributed to the stretching vibration of the C-H bonds in the PMEA and PMMA chains was observed at the air interface, this signal became weaker as the immersion time in water increased, implying that the polymer chains of the blend film at the interface were not very ordered in water.

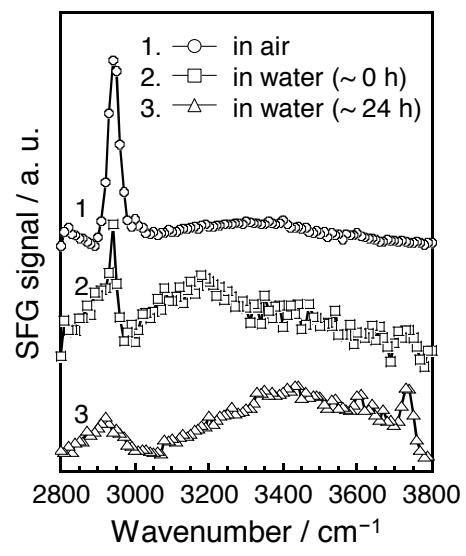

Fig. 3. SFG spectra for the PMEA/PMMA blend film at the air and $\mathrm{H}_{2} \mathrm{O}$ interfaces with the $s s p$ polarization combination. For the $\mathrm{H}_{2} \mathrm{O}$ interfaces, spectra were obtained immediately and at 24 $\mathrm{h}$ after water immersion.

Signals observed in the range $3000-3800 \mathrm{~cm}^{-1}$, which were attributed to the stretching vibration of O$\mathrm{H}$ bonds reflecting the state of water molecules under our experimental conditions, strongly depended on the surrounding environment $[31,32]$. At the air interface, a very broad and weak peak, which might be derived from the adsorbed water from the atmospheric environment, was observed. However, 
unfortunately, further discussion about the water structure based on this spectrum would be difficult due to the low intensity of the signal. On the other hand, a clear peak around $3200 \mathrm{~cm}^{-1}$, which was attributed to ordered water (relatively highly coordinated water) was immediately observed after water immersion $[24,37,38]$. When the polymer blend was immersed in water for $24 \mathrm{~h}$, the intensity of such a broad peak became weaker, and other peaks appeared at higher wavenumber regions in the range of 3600-3800 $\mathrm{cm}^{-1}$, which corresponds to a disturbed-network structure of water manifesting as dangling O-H $\left(\sim 3600 \mathrm{~cm}^{-1}\right)$ and free O-H $\left(\sim 3740 \mathrm{~cm}^{-1}\right)$, for example [31,32,39]. As previously reported, these lower coordinated or free waters are key to suppressing platelet adhesion on the polymer interface $[23,24]$. Although the $\phi_{\mathrm{PMEA}}(0)$ value was lower for the PMEA/PMMA (10/90) blend than for the PMEA/PMMA (50/50) blend by approximately 9 vol\%, water molecules at the interface were effectively disturbed.

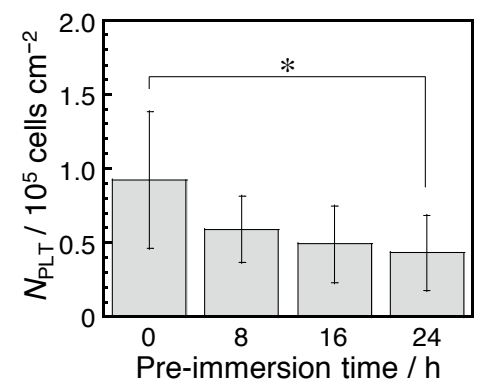

Fig. 4. Number of platelets $\left(N_{\mathrm{PLT}}\right)$ adhered to the various films with different water preimmersion times. Bars show the average counts with standard deviation $(n=3)$. ${ }^{*}, P<0.1$ (Student's $t$-test).

Finally, we come to the platelet adhesion behavior, often used as an indicator of the bloodcompatibility of materials, for the PMEA/PMMA (10/90) blend film in water $[18,21,23,24]$. Fig. 4 shows the number of platelets $\left(N_{\mathrm{PLT}}\right)$ adhered on the PMEA/PMMA (10/90) blend film at the water interface as a function of the pre-immersion time in water before the platelet adhesion tests. Interestingly, while a relatively large number of platelets adhered for the blend film without preimmersion in water, the $N_{\text {PLT }}$ values clearly decreased with increasing water immersion time. That is, the suppressibility of platelet adhesion increased with immersion time. The level of suppression was 
comparable to that for a homogeneous PMEA film as previously reported [24]. Thus, these results showed that only $10 \mathrm{wt} \%$ PMEA in the blend film was sufficient to express excellent bloodcompatibility at the water interface.

\section{Conclusions}

We demonstrated that a small amount of PMEA (10 wt $\%)$ blended in a PMMA film was segregated to the water interface and showed excellent blood-compatibility comparable to that of a homogeneous PMEA film. These results convince us that this simple surface modification method based on thermodynamically-driven segregation will contribute to the development of an increasing number biomedical devices requiring highly advanced functionalization.

\section{Acknowledgment}

We thank Dr. Y. Fujii, National Institute for Materials Science (NIMS), Japan, for advice on NR experiments and analysis. This research was partly supported by Grant-in-Aids for the Scientific Research on Innovative Areas "New Polymeric Materials Based on Element-Blocks" (15H00758) program to KT and for Scientific Research (A) (15H02183) to KT and Scientific Research (C) (15K05633) to HM from the Ministry of Education, Culture, Sports, Science and Technology, Japan. We also thank the support from the JST SENTANKEISOKU (13A0004) to KT. NR measurements were performed on BL-16 at the Materials and Life Science Facility, J-PARC, Japan, under program no. 2009S08 and no. 2014S08. 


\section{References}

[1] J. Sagiv, Organized monolayers by adsorption. 1. Formation and structure of oleophobic mixed monolayers on solid surfaces, J. Am. Chem. Soc., 1980, 102(1), 92-98.

[2] C. D. Bain, J. Evall, G. M. Whitesides, Formation of monolayers by the coadsorption of thiols on gold: variation in the head group, tail group, and solvent, J. Am. Chem. Soc., 1989, 111(18), $7155-7164$.

[3] C. Queffélec, M. Petit, P. Janvier, D. A. Knight, B. Bujoli, Surface modification using phosphonic acids and esters, Chem. Rev., 2012, 112(7), 3777-3807.

[4] R. A. L. Jones, E. J. Kramer, M. H. Rafailovich, J. Sokolov, S. A. Schwarz, Surface enrichment in an isotopic polymer blend, Phys. Rev. Lett. 1989, 62, 280-283.

[5] K. R. Shull, E. J. Kramer, G. Hadziioannou, W. Tang, Segregation of block copolymers to interfaces between immiscible homopolymers, Macromolecules, 1990, 23(22), 4780-4787.

[6] P. F. Green, T. P. Russell, Segregation of low molecular weight symmetric diblock copolymers at the interface of high molecular weight homopolymers, Macromolecules, 1991, 24(10), 2931-2935.

[7] C. M. Kassis, J. K. Steehler, D. E. Betts, Z. Guan, T. J. Romack, J. M. DeSimone, R. W. Lonton, XPS studies of fluorinated acrylate polymers and block copolymers with polystyrene, Macromolecules, 1996, 29(9), 3247-3254.

[8] M. Inutsuka, N. L. Yamada, K. Ito, H. Yokoyama, High density polymer brush spontaneously formed by the segregation of amphiphilic diblock copolymers to the polymer/water interface, ACS Macro Lett., 2013, 2(3), 265-268.

[9] K. Tokuda, M. Noda, T. Maruyama, M. Kotera, T. Nishino, A low-fouling polymer surface prepared by controlled segregation of poly(ethylene oxide) and its functionalization with biomolecules, Polymer J., 2015, 47(4), 328-333.

[10] A. Oyane, T. Ishizone, M. Uchida, K. Furukawa, T. Ushida, H. Yokoyama, Spontaneous formation of blood-compatible surfaces on hydrophobic polymers: surface enrichment of a block 
copolymer with a water-soluble block, Adv. Mater., 2005, 17(19), 2329-2332.

[11] R. Zhang, A. Seki, T. Ishizone, H. Yokoyama, Reduced hydrophobic interaction of polystyrene surfaces by spontaneous segregation of block copolymers with oligo (ethylene glycol) methyl ether methacrylate blocks: force measurements in water using atomic force microscope with hydrophobic probes, Langmuir, 2008, 24(10), 5527-5533.

[12] D. G. Walton, P. P. Soo, A. M. Mayes, S. J. Sofia Allgor, J. T. Fujii, L. G. Griffith, J. F. Ankner, H. Kaiser, J. Johansson, G. D. Smith, J. G. Barker, S. K. Satija, Creation of stable poly(ethylene oxide) surfaces on poly(methyl methacrylate) using blends of branched and linear polymers, Macromolecules, 1997, 30(22), 6947-6956.

[13] B. Zhao, W. J. Brittain, Polymer brushes: surface-immobilized macromolecules, Prog. Polym. Sci., 2000, 25(5), 677-710.

[14] R. Barbey, L. Lavanant, D. Paripovic, N. Schüwer, C. Sugnaux, S. Tugulu, H. A. Klok, Polymer brushes via surface-initiated controlled radical polymerization: synthesis, characterization, properties, and applications, Chem. Rev., 2009, 109(11), 5437-5527.

[15] R. Shishoo, Plasma Technologies for Textiles, 1st ed., Woodhead Publishing Limited, Cambridge, 2007.

[16] C. Labay, J. M. Canal, A. Navarro, C. Canal, Corona plasma modification of polyamide 66 for the design of textile delivery systems for cosmetic therapy, Appl. Surf. Sci. 2014, 316(15), 251-258.

[17] P. K. Chua, J. Y. Chen, L. P. Wang, N. Huang, Plasma-surface modification of biomaterials, Mater. Sci. Eng. R., 2002, 36(5-6), 143-206.

[18] F. S. Denes, S. Manolache, Macromolecular plasma-chemistry: an emerging field of polymer science, Prog. Polym. Sci., 2004, 29(8), 815-885.

[19] T. Hirata, H. Matsuno, M. Tanaka, K. Tanaka, Surface segregation of poly(2-methoxyethyl acrylate) in a mixture with poly(methyl methacrylate), Phys. Chem. Chem. Phys., 2011, 13(11), 4928-4934. 
[20] M. Tanaka, T. Motomura, M. Kawada, T. Anzai, Y. Kasori, T. Shiroya, K. Shimura, N. Onishi, A. Mochizuki, Blood compatible aspects of poly(2-methoxyethylacrylate) (PMEA) - relationship between protein adsorption and platelet adhesion on PMEA surface, Biomaterials, 2000, 21(14), $1471-1481$.

[21] M. Tanaka, A. Mochizuki, N. Ishii, T. Motomura, T. Hatakeyama, Study of blood compatibility with poly(2-methoxyethyl acrylate). Relationship between water structure and platelet compatibility in poly(2-methoxyethylacrylate-co-2-hydroxyethylmethacrylate), Biomacromolecules, 2002, 3(1), 36-41.

[22] M. Tanaka, T. Motomura, N. Ishii, K. Shimura, M. Onishi, A. Mochizuki T. Hatakeyama, Cold crystallization of water in hydrated poly(2-methoxyethyl acrylate) (PMEA), Polym. Int., 2000, 49(12), 1709-1713.

[23] T. Hirata, H. Matsuno, D. Kawaguchi, T. Hirai, N. L. Yamada, M. Tanaka, K. Tanaka, Effect of local chain dynamics on a bioinert interface, Langmuir, 2015, 31(12), 3661-3667.

[24] T. Hirata, H. Matsuno, D. Kawaguchi, N. L. Yamada, M. Tanaka, K. Tanaka, Effect of interfacial structure on bioinert properties of poly(2-methoxyethyl acrylate)/poly(methyl methacrylate) blend films in water, Phys. Chem. Chem. Phys., 2015, 17(26), 17399-17405.

[25] T. G. Fox, Bull. Am. Phys. Soc., 1956, 1, 123.

[26] P. J. Flory, in Principle of Polymer Chemistry, Cornell University, Press, Ithaca, New York, 1953, Chap. 12, pp. 495-540.

[27] N. L. Yamada, N. Torikai, K. Mitamura, H. Sagehashi, S. Sato, T. Sugita, S. Goko, M. Furusaka, T. Oda, M. Hino, T. Fujiwara, H. Takahashi, A. Takahara, Design and performance of horizontaltype neutron reflectometer SOFIA at J-PARC/MLF, Eur. Phys. J. Plus, 2011, 126, 108.

[28] K. Mitamura, N. L. Yamada, H. Sagehashi, N. Torikai, H. Arita, M. Terada, M. Kobayashi, S. Sato, H. Seto, S. Goko, M. Furusaka, T. Oda, M. Hino, H. Jinnai, A. Takahara, Novel neutron reflectometer SOFIA at J-PARC/MLF for in-situ soft-interface characterization, Polym. J., 2013, 
$45,100-108$.

[29] K. Tanaka, Y. Fujii, H. Atarashi, K. Akabori, M. Hino, T. Nagamura, Nonsolvents cause swelling at the interface with poly(methyl methacrylate) films, Langmuir, 2008, 24(1), 296-301.

[30] A. Horinouchi, N. L. Yamada, K. Tanaka, Aggregation states of polystyrene at nonsolvent interfaces, Langmuir, 2014, 30(22), 6565-6570.

[31] Q. Du, E. Freysz, Y. R. Shen, Vibrational spectra of water molecules at quartz/water interfaces, Phys. Rev. Lett., 1994, 72(2), 238-241.

[32] G. L. Richmond, Molecular bonding and interactions at aqueous surfaces as probed by vibrational sum frequency spectroscopy, Chem. Rev., 2002, 102(8), 2693-2724.

[33] S. Ye, S. Morita, G. Li, H. Noda, M. Tanaka, K. Uosaki, M. Osawa, Structural changes in poly(2methoxyethyl acrylate) thin films induced by absorption of bisphenol A. An infrared and sum frequency generation (SFG) study, Macromolecules, 2003, 36(15), 5694-5703.

[34] Y. Tateishi, N. Kai, H. Noguchi, K. Uosaki, T. Nagamura, K. Tanaka, Polym. Chem., Local conformation of poly(methyl methacrylate) at nitrogen and water interfaces, 2010, 1(3), 303-310.

[35] H. Yokoyama, T. Miyamae, S. Han, T. Ishizone, K. Tanaka, A. Takahara, N. Torikai, Spontaneously formed hydrophilic surfaces by segregation of block copolymers with watersoluble blocks, Macromolecules, 2005, 38(12), 5180-5189.

[36] R. A. L. Jones, R. W. Richards, Polymers at Surfaces and Interfaces; Cambridge University Press, 1999.

[37] S. Nihonyanagi, S. Yamaguchi, T. Tahara, Water hydrogen bond structure near highly charged interfaces is not like ice, J. Am. Chem. Soc., 2010, 132(20), 6867-6869.

[38] S. Nihonyanagi, T. Ishiyama, T. Lee, S. Yamaguchi, M. Bonn, A. Morita, T. Tahara, Unified molecular view of the air/water interface based on experimental and theoretical $\chi(2)$ spectra of an isotopically diluted water surface, J. Am. Chem. Soc.,. 2011, 133(42), 16875-16880.

[39] H. Kusanagi, S. Yukawa, Fourier transform infra-red spectroscopic studies of water molecules 
sorbed in solid polymers, Polymer, 1994, 35(26), 5637-5640. 


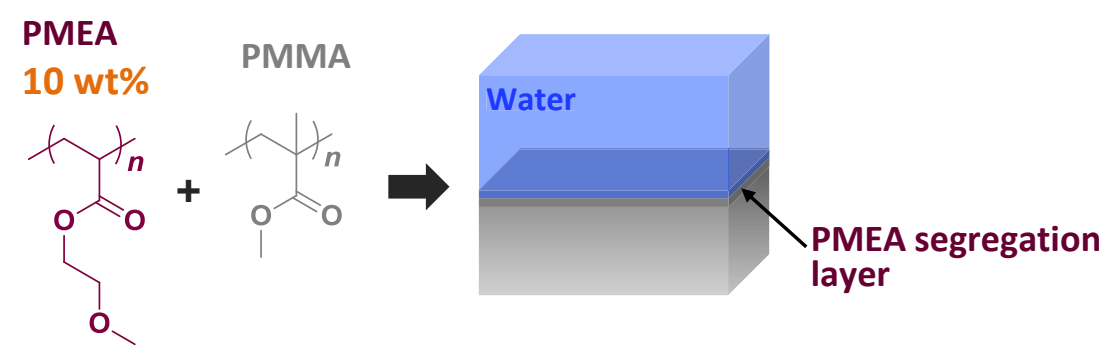

